\title{
Cape Saint Paul Wilt Disease of coconut in Ghana: surveillance and management of disease spread
}

\author{
Joe NKANSAH-POKU \\ René PHILIPPE ${ }^{2}$ \\ Robert Nketsia QUAICOE ${ }^{1}$ \\ Sylvester Kuuna DERY ${ }^{1}$ \\ Arthur RANSFORD ${ }^{3}$ \\ ${ }^{1}$ CSIR - OPRI, Coconut Programme, \\ P.O. Box 245, Sekondi, Ghana \\ <nkansahpoku@yahoo.com> \\ 2 UPR 29, CIRAD - BIOS, \\ Campus Int de Baillarguet, \\ 34398 Montpellier, France \\ ${ }^{3}$ CSDP, Ministry of Food \& Agriculture, \\ P.O. Box 245, Sekondi, Ghana
}

\begin{abstract}
The Cape Saint Paul Wilt Disease (CSPWD), a lethal-yellowing type disease of coconut has been in Ghana since 1932. Aerial and/or ground surveys were undertaken to assess the current status of the disease spread. The survey showed that the spread of the disease for the past 5 years has mainly been the expansion of existing foci. However, new outbreaks were identified at Glidzi in the Volta, Bawjiase and Efutu Breman in Central regions. After the resurgence in the Volta region in 1995, the Woe-Tegbi-Dzelukope corridor has remained endemic, but less aggressive. Pockets of healthy groves remain along all the coastline and inland of known disease zones. Eradication of diseased palms at Ampain focus lying just about $60 \mathrm{~km}$ to the Ivorian border, and disease situations on new replanting with MYD $\times$ VTT hybrid are discussed.
\end{abstract}

Key words: Cape Saint Paul Wilt Disease, coconut, aerial survey, disease management
The Cape Saint Paul Wilt Disease (CSPWD), a lethal-yellowing type disease of coconut has been in Ghana since 1932. The disease is caused by a phytoplasma and is found in Africa and the Caribbean. The symptoms of the disease are premature nut drop with or without yellowing of fronds and blackening of immature inflorescences. This is followed by progressive yellowing or in some instances browning of the crown from the older leaves upwards. Eventually, the crown turns yellow, dries up and then falls off, leaving a bare trunk or "telephone pole".

Two types of spread of CSPWD have been observed. In one type, a local centre of infection appears in one or two palms; this is followed by new cases appearing at random around the initial centre. The second is a "jump spread" whereby the disease appears at a spot remote from a known focus. This is then followed by a local spread in all directions.

The disease epidemic which began around Cape Saint Paul in Woe near Keta destroyed thousands of coconut palms and caused the collapse of the coconut industry in the Volta region by the mid-1950s [1]. The disease appeared in the Western region at Cape Three Points in 1964 and in the Central region at Ayensudo in 1983. The history, occurrence, epidemiology and spread of the disease in Ghana have been reported by Johnson and Harries [2], Ofori and Nkansah-Poku [3] and Dery et al. [4].
McCoy et al. [5] pointed out that most secondary spread of lethal yellowing disease occurs within $100 \mathrm{~m}$ of a new focus and eradication could be useful if practised rigorously in the early stages of the outbreak. Philippe et al. [6] and Nkansah-Poku et al. [7] observed that cutting out regularly all diseased palms slows down the rate of spread of CSPWD.

Since 2000 the damage and spread of the disease have been monitored through disease surveys. In 2006 and 2007, an aerial surveillance was conducted to have a quick view of the extent of the disease spread in the Western region. These were the only occasions ever of monitoring the CSPWD spread with an aircraft in the country. The disease has also been managed by removal of diseased palms in a focus at Ampain to reduce the disease spread westwards to protect the large healthy plantings beyond Ampain.

The hybrid between the "Malayan Yellow Dwarf" and "Vanuatu Tall" (MYD × VTT) was used in a rehabilitation programme in 1999 following a recommendation by Dery et al. [8]. Between 1999 and 2004, 1,300 ha of devastated areas were replanted with this hybrid in the Western and Central regions.

This paper reports and discusses the aerial surveillance, current disease distribution in the Volta, Central and Western regions, containment of the disease at Ampain as well as the disease situation on new replanting plots with the hybrid, MYD $\times$ VTT.

\section{Materials and methods}

\section{CSPWD survey}

\section{Aerial surveillance}

A small two-seater ULM aircraft was used in the survey. The aircraft moved at an average speed of about $35 \mathrm{~m} / \mathrm{s}$ and at a height of approximately $300 \mathrm{~m}$. Waypoints of suspected diseased coconut palms/foci spotted from the aircraft were recorded with a "Global Positioning System 60" (Garmin Ltd). Recorded waypoints were estimated in metres to the left, centre or right of the aircraft from the spotted diseased palms/foci and managed with MapSource software for assessment and ground verification. Photographs were also taken of suspected CSPWD infection spots. The aircraft flew along designed flight patterns worked out by the research team and the pilot.

\section{Ground surveillance}

Two types of ground survey were conducted. The first was an extensive survey aimed at covering all the coconut-growing regions. In this type, we made use of accessible footpaths and motorable routes in an area to inspect coconut plantations. Village enquiries and interviews of 
farmers and agriculture extension agents were carried out to gain information on the presence or absence of the disease in an area. The second was an intensive survey aimed at identifying diseased spots and or individual diseased palms in an infected plantation or nearby healthy farms, which are at risk of getting infected. The "systematic walk through" method was used to locate palms with visible CSPWD symptoms in an area. Samples of infected palms were taken for polymerase chain reaction (PCR) analysis to confirm disease incidence. Known diseased foci were monitored monthly in this way. GPS points captured during aerial surveillance were also verified by this method.

\section{Disease management/containment}

To reduce the rate of spread of the disease, eradication of diseased palms was undertaken at the Ampain focus. There is a continuous stretch of coconut planting from this focus westwards to Cote d'Ivoire. The focus was monitored periodically and monthly in times of sufficient logistics. During each visit, palms were inspected and those showing disease symptom were felled with a chain saw machine, fronds pruned off and trunk cut into pieces of a metre long to facilitate quick drying.

\section{Monitoring of Coconut Sector Development Project (CSDP) replanted plots}

The CSDP of the Ministry of Food and Agriculture (MoFA) started a rehabilitation programme with the MYD $\times$ VTT hybrid from 1999, and 1300 ha was replanted by 2004 under a project funded by Agence Francaise de Developpement (AFD). All fields replanted with the hybrid were monitored between March 2006 and May 2007 through monthly inspections. All cases of disease development based on visual symptoms were recorded. First infection cases in each plot were verified and then confirmed by PCR analysis.

\section{Results}

\section{Aerial surveillance}

Two surveys were conducted, the first from August 28 to August 31, 2006 and the second, March 25-March 30, 2007. The first survey was conducted in the area denoted as "established infection area" (figure 1). Two incipient foci were revealed by that survey, one to the north and the other to the west of Salman $15.2 \mathrm{~km}$ and $11.2 \mathrm{~km}$ away from the coast, respectively, following ground verification of points captured with GPS. These foci were beyond the previously known disease front. In the second survey, the area covered extended close to the frontier with Cote d'Ivoire but $2 \mathrm{~km}$ away from the border for security reasons. The disease appeared to have established itself in the approximate pattern shown in figure 1. The extent of the survey is denoted by the mauve line and the areas of possible and established infection delimited in red. The green delimited area was not surveyed because it appeared to be a "coconut-free zone". The "possible new infection area' had coconuts with a general yellowing tinge to the lower leaves over a large area, which runs down towards the frontier with Cote d'Ivoire. Isolated cases of yellowing were also found in other areas.

\section{Ground verification survey}

Using the data captured on the GPS and the aerial photographs (figure 2) taken during the

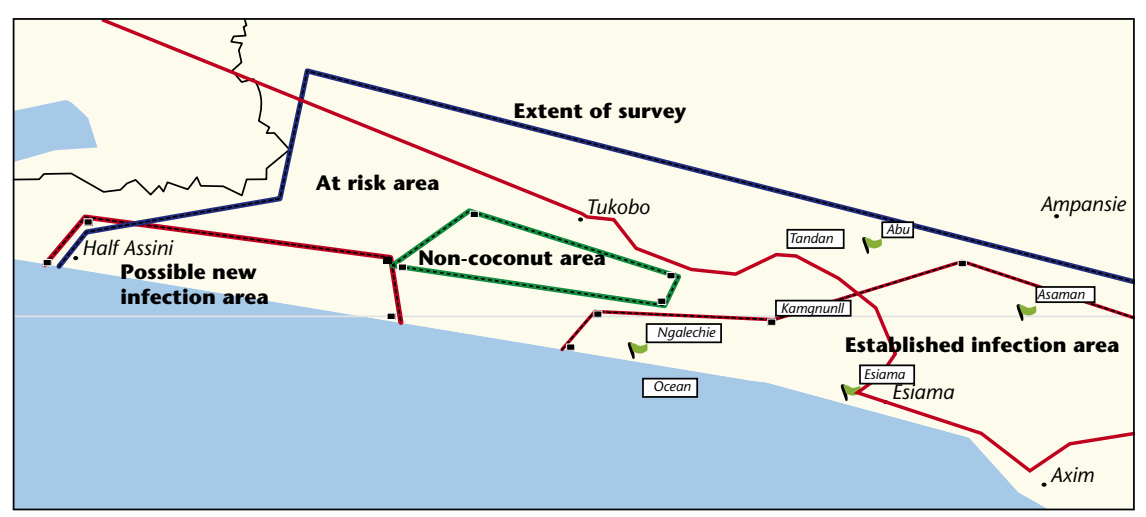

Figure 1. Area covered by aerial surveillance.

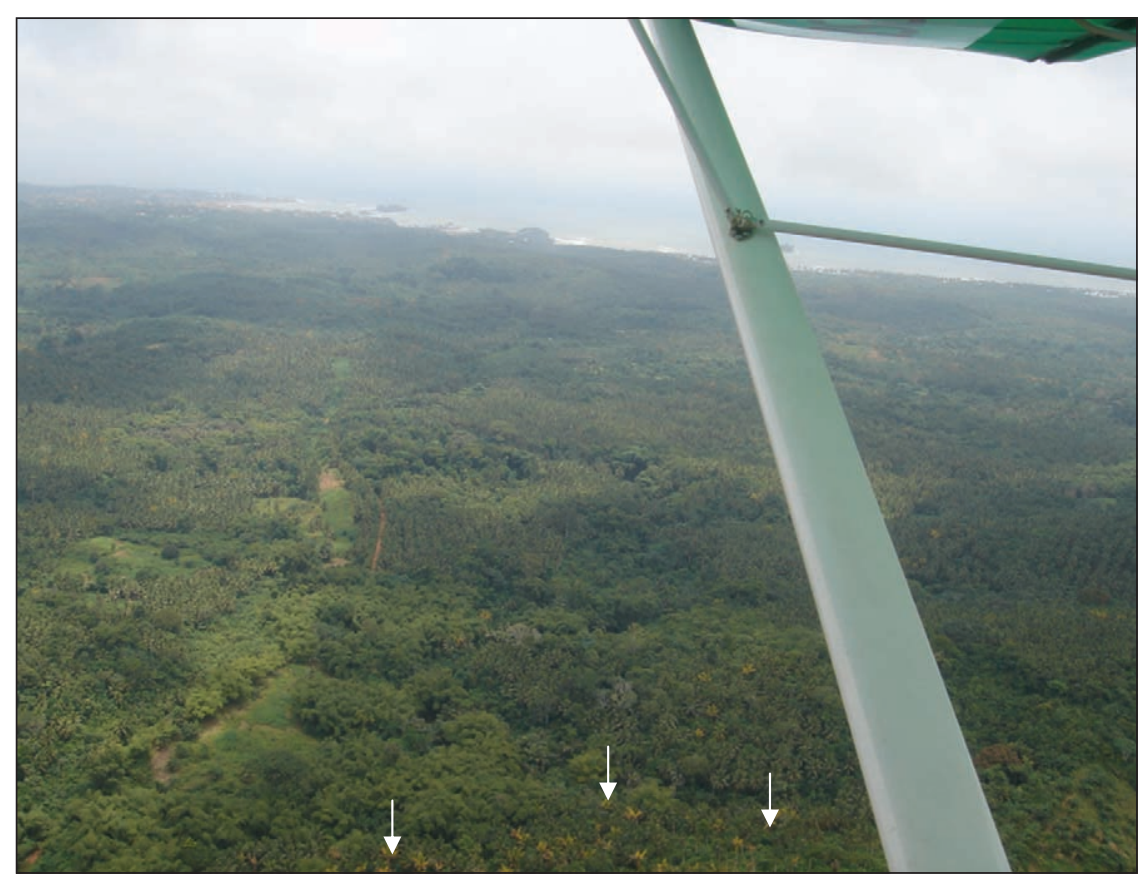

Figure 2. Photograph taken during the aerial survey showing diseased palms (arrowed). flights, ground survey for the verification of the GPS captured disease symptoms was conducted in the area marked "possible new infection area" and beyond Half Assini all the way to the frontier. A thorough ground search identified GPS points 041 (southeast of Tikobo 2) and 167 (near Half Assini). Samples from representative CSPWD suspected palms within the designated area were taken for PCR analysis. A total of six samples from six locations were analysed. Morphology of the sampled palms ranged from symptoms of pronounced yellowing reminiscent of nitrogen deficiency, yellowed lower crown with dark spotting in the lamina resembling symptoms of potassium deficiency and pale crowns with tapering trunks as in senile palms on poor soil. All the palms tested negative, thus confirming the absence of the disease in these palms. 
A critical observation of these suspected disease outbreak points showed that apart from two locations, where there were intercropping with maize, cassava and vegetables, all the palms had been left to grow without any agronomic intervention and were associated with bushy undergrowths. All the target palms were West Africa Tall (WAT) ecotypes above 40 years and showing poor nut loads. Apart from yellowing of lower leaves, no other symptom, for example, nut drop or necrosis of opened inflorescences, was observed in any of the suspected palms.

\section{Limit of spread of CSPWD}

The disease zone stretches from Ampain in the west to Keta in the east along the coast. However, there are pockets of healthy groves remaining in between and further inland. The figures 2 and 3 show the current distribution of the CSPWD incidence in Ghana.

\section{Disease distribution in the Western region}

The worst affected district in the region is the Ahanta West, which has lost about $70 \%$ of its coconut plantings. Few healthy groves now exist and the disease appeared less active in existing foci.

The most active foci are located in the Nzema East district. The Asanta focus appeared in 1992 and by 2001 had almost devastated all the coconuts in the area ( $90 \%$ loss) crossing the river Ankobra lying in the east to merge with the Awuku focus established in 1990, which had also spread westwards through Axim. The Asanta focus has spread as far north as Nyamebekyere by 2006. Another focus at Ampain since its identification in 1995 has expanded the least in the district, despite the loss of $70 \%$ of the original 25 ha planting. About $20-30 \%$ of the district's 12,000 ha of coconuts are lost. Two other active foci in the region are located at Botogyina and Daboase (figure 3) in the Shama and Mpohor Wassa East districts, respectively. The spread after 1995 has mainly been by expansion of existing foci rather than jump spread.

\section{Disease distribution in the Central region}

In the Central, the disease was spotted at Ayensudo near Komenda in 1983. By 1995, there were several foci dotted in the KEEA district. These foci merged in 1998 and devastated all the plantings around Abrobiano, Duakyimase and Kafodzidzi. The foci at Dompoase, Ayensudo and Ataabadze lying north of Komenda also merged and spread to Hemang and Dwabor further north by 2003. The recent survey showed only scattered infected fields with varied damage levels (1-70\%) in the northern part of the district where coconut plantations are not continuous - coconut plots are separated by food crop farms.

The Eduma focus established in 1989 had expanded north to merge with the Abakrampa focus engulfing the plantings at Asebu and its environs, reaching Asuansi in 2006. Another active disease centre of interest in the region is the Asaafa-Narkwa corridor. The disease occurred at Asaafa in 1998 and Narkwa in 1996. These foci had since merged and devastated about $60 \%$ of the plantations as at April 2008. Beyond Narkwa towards the east, the disease had spread to Mumford near Apam. The loss in this zone is about $40-60 \%$.

The Agona district which was previously disease free is now affected. An outbreak occurred in 2006 Obratwawu near Bawjiase and about 650 palms (less than 1\%) of the original stand had succumbed to the disease by April 2008.

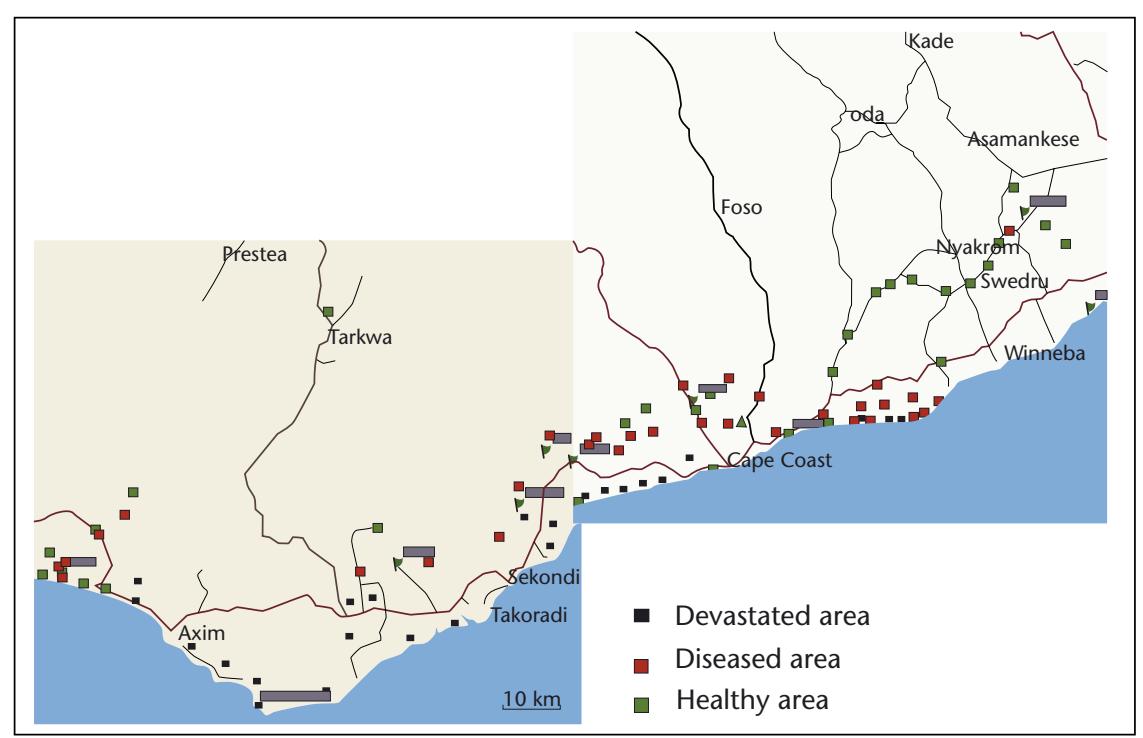

Figure 3. Cape Saint Paul wilt disease (CSPWD) distribution in the Western and Central regions of Chana.

Figure 4. Cape Saint Paul wilt disease (CSPWD) distribution in the Volta region.
This focus is of importance because it is at the centre of one of the extensive coconut groves in the region and it seriously threatens the supply of fresh nuts to Accra, the capital city of Ghana. Another outbreak occurred at Efutu Breman near Jukwa in 2005 and by 2008 devastated about 1.5 ha.

\section{Disease distribution in the Volta region}

In the Volta region, the disease is currently less active with losses between 0 and $2 \%$. Existing disease foci are shown in figure 4. After the major epidemic in 1960s and 1970s in the Keta area, the disease apparently disappeared until 1995 when it resurfaced to attack replanted fields [3]. However, the disease after resurgence had been less aggressive and its attack is sporadic and mainly centred around the Woe-Tegbi-Dzelukope corridor. It has remained endemic at the Cape Saint Paul area

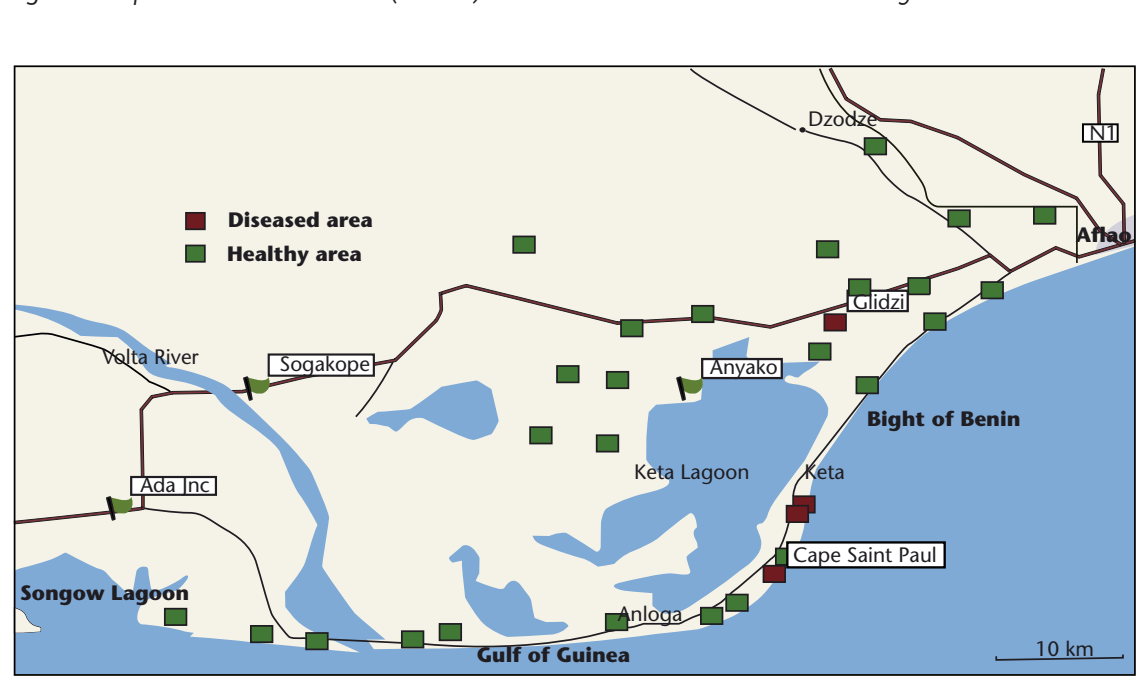


in Woe. Losses are very low and the economic impact appears negligible. Only very few diseased palms were observed at the corridor during the last five surveys conducted between 1997 and 2008. A new outbreak was identified at Glidzi-Agbosome in 2006 with nine infected palms. Thus, the presence of the disease since 1995 had been in few locations around the Keta lagoon with minimal losses. Less than $1 \%$ loss had been recorded of the estimated 1,500 ha of coconut currently in the southern portion of the region.

\section{Disease management by removal of diseased palms}

The CSPWD focus at Ampain is the western front of the disease zone along the coast. An estimated 3800 coconut palms covering an area of 25 ha surrounded the main focus identified in 1995. Seventy percentage of the original stand has succumbed to the disease leaving about 30\% (1,130 palms) in existence as at March 2008. Of the percentage that was infected, 1,331 palms were removed by cutting out through containment exercise undertaken since 1996. However, due to funding problems, cutting was not done regularly through the period except 2003-2004 and from August 2007 to March 2008. However, field observation shows a slow spread of the disease at this focus.

\section{Disease spread in CSDP replanted plots}

Between 1999 and 2004, 1300 ha of devastated areas were replanted by CSDP with the MYD $\times$ VTT hybrid. Approximately 1,000 farmers were involved in the programme and had plot sizes of 1-3 ha in the Western and Central regions. In all, 1288 ha monitored for CSPWD infection (929 and 359 ha respectively in Western and Central regions) and 62 ha (4.8\%) (29 and 33 ha, respectively, in the Western and Central regions) were observed and confirmed by PCR analysis to be infected by the disease. None of the plantings of 1999 covering 35 ha (22 in Western and 13 in Central) and of 2004 covering 196 ha (176 in Western and 20 in Central) was affected by the disease as at May 2007. When the programme began in 1999, planting sites were carefully selected unlike the subsequent years. The affected plots were mostly planted in 2000, 2001 and in the mixed year plantings. The disease incidence was slightly higher in the Central region (33 ha) than in the Western region (29 ha) (figure 5).

\section{Discussion}

Coconut varieties in plantations in Ghana are mostly local WAT ecotypes. Their susceptibility to the CSPWD is very high. The pattern of the

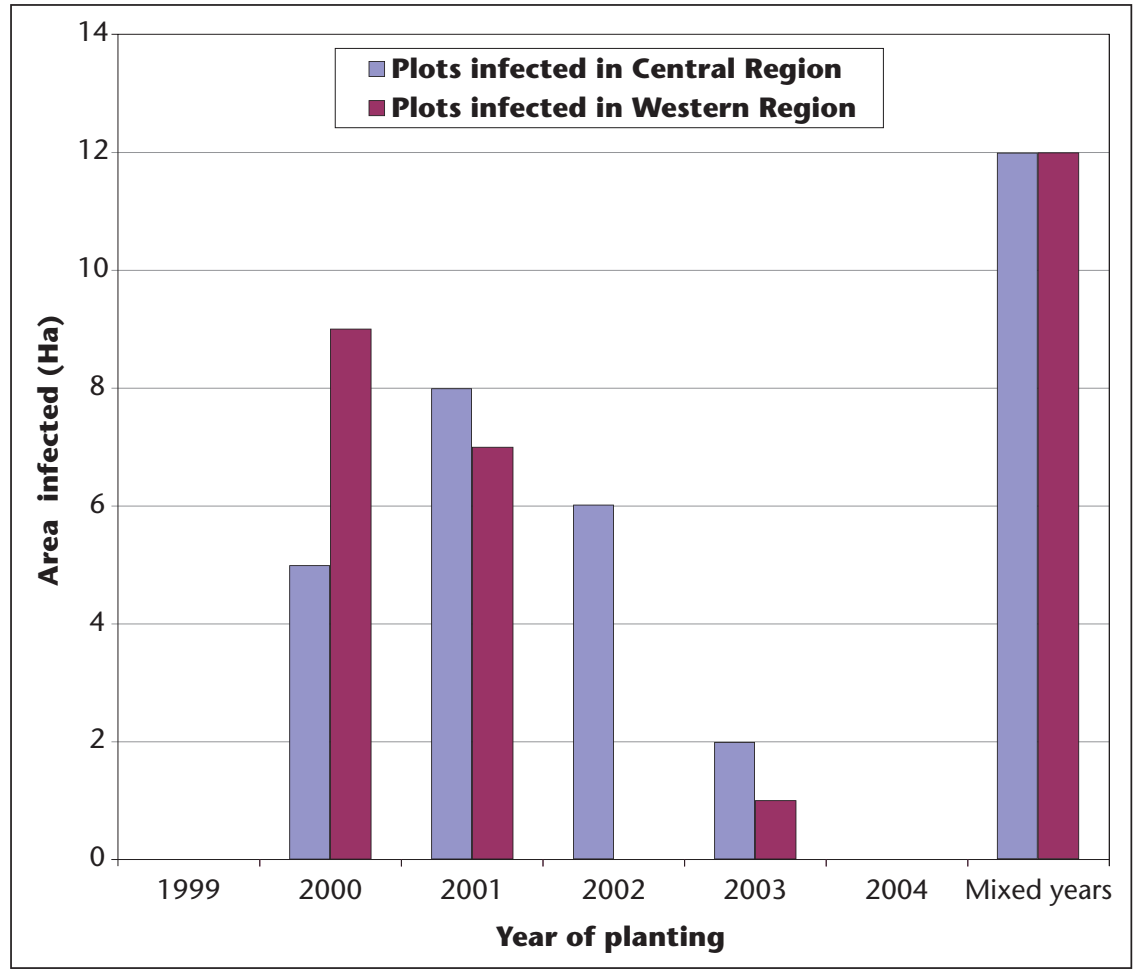

Figure 5. Cape Saint Paul wilt disease (CSPWD) distribution in MYD $\times$ VTT plots in Central and Western regions as at May 2007. disease spread appears erratic occurring in "leaps" or "jumps" characteristic of insect transmission as in Caribbean lethal yellowing disease [9]. However, some healthy palms can be observed even in heavily diseased farms.

The yellow patches in the "possible infection area" (figure 1) observed in the aerial survey were not CSPWD. It is a known fact that most of the coconut palms in the south western part of the Western region suffer from nutrient deficiencies, notably potassium, phosphorus and magnesium [10]. Most of the palms in the area are almost senile. Both nutrient deficiency and senescence result in some yellowing of the crown of the palms. These phenomena coupled with a high rate of lightning strikes prevalent in the area present an extensive area of yellowing of coconut palms, a feature which could easily be mistaken for CSPWD.

The aerial surveillance provides a quick view of the condition of coconut palms over a large area at a very short time. It is able to spot incipient foci as palms showing yellowing symptom singly or collectively can be spotted from the air and captured on GPS. This is dependent on the speed and height at which the aircraft travels. Captured data on GPS were detected within the radius of $300 \mathrm{~m}$ on the ground. As indicated above, not all palms showing yellowing symptoms are necessarily CSPWD infected. Thus, the method is not foolproof in identifying all CSPWD infections. To achieve that it has to be supported by ground surveillance to confirm disease infection. Another major drawback is that it is very expensive and cannot be done frequently without adequate resources. Aerial surveillance would be appropriate for early detection of incipient foci and half-yearly surveys are recommended to be conducted in the large healthy zone lying west of Ampain.

The rate of spread of the disease at Ampain is slow. From field observations, the estimated rate of spread per year of CSPWD is $0.33 \mathrm{~km}$ (about $1 \mathrm{~km}$ per 3 years). However, the spread around the disease focus at Ampain is less than $1 \mathrm{~km}$ for the past 14 years. Comparatively, the Asanta focus which had similar features (both foci established almost at the same time in coconut groves near swampy mangrove area, on outskirts of settlements less than $1 \mathrm{~km}$ to the coast, original coconut stands mainly of WAT subpopulations, dominant putative vector species encountered frequently at both sites were of the families of Derbidae, Cicadellidae, Diaspinae, Achilidae and (ixiidae) except the periodic cutting (done once in 1994 at Asanta) had expanded more than $3 \mathrm{~km}$ to the east crossing the river Ankobra, $3.3 \mathrm{~km}$ to the west reaching Kikam and more than $4 \mathrm{~km}$ to the north. The slow spread at Ampain is attributed mainly to the containment exercises that have been undertaken at the focus since 1996. Although not 
rigorously practised, the containment exercise had slowed down the spread of the disease in this area. This agrees with the observations of Philippe et al. [6] and Nkansah-Poku et al. [7] that cutting out regularly all diseased palms slow down the rate of spread of the disease. Felling reduces accumulation of disease inocula in a given plot. Eradication must be part of an integrated control strategy of CSPWD. Its contribution will be to reduce the amount of inoculum present at any point in time for vector acquisition and transmission. A programme based on early detection and prompt removal of diseased palms to control disease spread is recommended to cover a wider area.

The behaviour of the disease in the southeastern portion of the country presents a unique situation. The disease disappeared after the major epidemic in the 1960s and 1970s and recurred in 1995. Since then its attack has been sporadic and less aggressive, and losses very low compared to that in the Western and Central regions. The low incidence may be attributed to the following field conditions. There is a relatively drier condition prevalent here. Coconut mainly grows in sandy dry soils around the Keta lagoon and the narrow coastal strip of land between the sea and the lagoon. Due to intense pressure on land development of settlements under the plantations is a common feature; hence, there is little ground cover. Flora diversity is low and insects' vector population and activity have been observed in the field to be sparse. Planting materials used for replanting the devastated fields after the epidemic have come from diverse sources and thus, presence of heterogeneous coconut subpopulations. These factors probably are influ- encing the variation in disease spread in the region. It would be interesting to begin comparative studies into the disease spread in the Volta and Western regions.

The disease attack on the MYD $\times$ VTT hybrid in replanted fields appears low for now. However, it showed the susceptibility of the hybrid to high pressure of CSPWD as found on the fields in the Central region. In some fields, palms were killed even before flowering. However, as suggested by Dery et al. [11] the hybrid MYD $\times$ VTT should be given the preference in areas where the risk of disease attack is low due to its favourable agronomic performances and the fact that supplies of a superior hybrid are currently limited.

Acknowledgements. We are grateful to the Agence Francaise de Developpement (AFD), the French Embassy and the Government of Chana for providing funds for the work. We acknowledge the services of Mr Jonathan Porter, the pilot who flew the team safely.

\section{REFERENCES}

1. Leather RL. Further investigation into Cape Saint Paul wilt of coconuts of Keta, Ghana. Empire Journal of Experimental Agriculture 1959; 27: $67-78$

2. Johnson CG, Harries HC. A survey of Cape Saint Paul wilt of coconut in West Africa. Chana Journal of Agricultural Science 1976; 9: 125-9.

3. Ofori F, Nkansah-Poku J. Cape Saint Paul wilt disease of coconut in Ghana: History of its occurrence and spread. In: Eden-Green SJ, Ofori F, eds. Proceedings of an International Workshop on Lethal Yellowing-Like Diseases of Coconut,
Elmina, Chana, November 1995. Chatham, UK: NRI, p. 27-32, 1997.

4. Dery SK, Philippe R, Nkansah-Poku J. The history and epidemiology of CSPWD of coconut in Ghana. Journal of the Chana Science Association 1999; 1: 32-42.

5. McCoy RE, Thomas DL, Condo JK. Lethal Yellowing: why the quarantine? Nurseryman 1976; 21: 49-52.

6. Philippe R, Dery SK, Nkansah-Poku J. New data on a cultural control method against coconut lethal yellowing in Ghana. Cord 2004; 20: 21-7.

7. Nkansah-Poku J, Dery SK, Philippe R. Reduction of spread of Cape Saint Paul wilt disease (CSPWD) of coconut by insecticidal hotfogging and removal of diseased palms. Chana Journal of Agricultural Science NARS 2005; 1: 193-8.

8. Dery SK, N'cho YP, Sangare A, Arkhurst, ED. Cape Saint Paul wilt disease: Resistance screening and prospects for rehabilitating the coconut industry in Ghana. In: Eden-Green SJ, Ofori $\mathrm{F}$, eds. Proceedings of an International Workshop on Lethal Yellowing-Like Diseases of Coconut, Elmina, Ghana, November 1995. Chatham, UK: NRI, p. 147-151, 1997.

9. McCoy RE, Howard FW, Tsai JH, et al. Lethal Yellowing of Palms. University of Florida Agricultural Experiment Stations Bulletin 834. Florida, USA, 1983.

10. Bonneau X, Dery SK, Andoh-Mensah E. CSDP Mission Report CP-SIC 1497, 2002.

11. Dery SK, Philippe R, Baudouin L, et al. Genetic diversity among coconut varieties for susceptibility to Cape Saint Paul Wilt Disease. Euphytica 2008; 164: 1-11. 